\title{
Testicular adrenal rest tumors in boys with 21-hydroxylase deficiency, timely diagnosis and follow-up
}

\author{
Mirjana Kocova', Vesna Janevska ${ }^{2}$ and Violeta Anastasovska ${ }^{3}$ \\ ${ }^{1}$ Department of Endocrinology and Genetics, Medical Faculty, University Pediatric Clinic, Ss. Cyril and Methodius University, Skopje, Republic \\ of Macedonia \\ ${ }^{2}$ Institute of Pathology, Medical Faculty, Ss. Cyril and Methodius University, Skopje, Republic of Macedonia \\ ${ }^{3}$ Genetic Laboratory, Medical Faculty, University Pediatric Clinic, Ss. Cyril and Methodius University, Skopje, Republic of Macedonia
}

Correspondence should be addressed to M Kocova: mirjanakocova@yahoo.com

\begin{abstract}
Background: Testicular adrenal rest tumors (TARTs) are found in 30-94\% of adult males with congenital adrenal hyperplasia (CAH). We sought to explore TART appearance through yearly ultrasound examination of testes in young boys with $\mathrm{CAH}$, and its association with metabolic control and genetic mutations.

Methods: Twenty-five boys with 21-hydroxylase deficiency in the age group 4-18 years diagnosed during the period 2001-2016 were included in the study. ACTH, 17-hydroxyprogesterone, androstenedione and testosterone were measured at 4-month intervals. Growth and BMI were assessed at the time of evaluation. PCR/ACRS method was used for CYP21A2 gene analysis. Testicular ultrasound examination was performed yearly.

Results: TARTs were detected by ultrasound in 8 children at the age of 6-16 years (13.2 years average). Five had salt-wasting form, two had simple virilizing form and one had non-classic form of CAH. Significant differences in the17OHP and androstenedione levels were detected between the boys, adherent and non-adherent to therapy. Inadequate metabolic control was not different in boys with and without TART (11/17 and 5/8 respectively). No significant difference was detected in the distribution of genetic mutations or adherence to therapy between patients with and without TARTs. One patient had a mutation not reported thus far in TART and another developed leukemia.

Conclusion: TART is not rare in young boys with $\mathrm{CAH}$, irrespective of the specific mutation or metabolic control. Ultrasound screening helps timely diagnosis and adjustment of therapy.
\end{abstract} Key Words

- 21-hydroxylase deficiency

- CYP21A2 gene

- metabolic control

- testicular adrenal rest tumors

- ultrasound

\section{Introduction}

Congenital adrenal hyperplasia $(\mathrm{CAH})$ is most frequently caused by deficiency of 21-hydroxylase, a key enzyme in the mineralocorticoid and glucocorticoid synthesis pathways in humans. It is a rare autosomal recessive disease with a frequency of $1: 15,000(1,2)$. However, heterozygosity is frequent in this disease, especially in certain populations
(3). The clinical forms of CAH are classified as classical and non-classical. The classical forms are the salt wasting (SW) form (2/3 of patients) and simple virilizing (SV) form ( 1/3 of patients), requiring long-standing therapy with hydrocortisone and fludrocortisone and careful titration to avoid overdosing. Major complications of the http://www.endocrineconnections.org https://doi.org/10.1530/EC-18-0097 (c) 2018 The authors Published by Bioscientifica Ltd

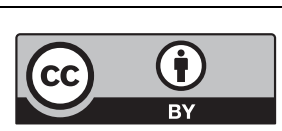

This work is licensed under a Creative Commons Attribution 4.0 International License. 
disease and the therapy are shorter than expected stature, obesity, metabolic syndrome and infertility (1, 2, 4). Fertility problems in adult male patients with $\mathrm{CAH}$ have been attributed to the development of testicular adrenal rest tumors (TARTs) $(3,4,5)$. The migration of adrenal cells during embryonic development can involve extraadrenal regions, such as the retroperitoneum, ovaries and testes. These adrenal cells undergo atrophy later during the development if the hormonal status of the individual is normal. However, if the adrenocorticotropic hormone (ACTH) level in the serum is high, as is frequently the case in patients with $\mathrm{CAH}$, these 'ectopic' adrenal cells might multiply to a level of severe tumor-like hyperplasia affecting the testicular tissue and causing infertility later in life $(5,6)$. TART lesions were first described as early as 1940, but the risk factors, genetic associations and optimal therapy are still under debate. Most studies assessing the incidence of TART include adult patients or both children and adults. The usual age at diagnosis is $20-40$ years with a variable prevalence reaching up to $94 \%$ $(4,5,6,7)$. Some recent studies show that it can also affect younger boys (8). Severe CYP21A2 gene mutations, late diagnosis, non-compliance and difficulties in managing $\mathrm{CAH}$, e.g. maintaining ACTH values within acceptable levels can increase the likelihood for $\operatorname{TART}(8,9,10,11)$. However, these findings have been disputed $(12,13)$. No international guidelines for follow-up of male children with CAH and TART are available. New ENDO guidelines for $\mathrm{CAH}$ are in a process of comment before publication.

Here, we describe the experiences of a single center treating children with $\mathrm{CAH}$ associated with TART. The detection of TART relied on yearly testicular ultrasonography check-ups starting at the age of 4 years. The study covers a 15-year follow-up period. These findings increase the limited data on TART in children and contribute to the assessment of the diagnostic value of ultrasound and possibly to the development of follow-up algorithms.

\section{Subjects and methods}

During the period 1991-2015, 71 patients (30 males) with all forms of $\mathrm{CAH}$ were diagnosed at the University Pediatric Clinic in Skopje, covering the entire pediatric tertiary care of the Republic of Macedonia. Written consent for yearly testicular ultrasonographic check-up was obtained by the parents of each patient. The study was conducted according to the declaration of Helsinki, revision of 2008.
It was approved by the Ethical committee at the University Pediatric Clinic.

The diagnosis of CAH was based on the international guidelines (14). Testicular enlargement was detected in only one boy. Molecular analysis was performed using the polymerase chain reaction/amplification creation restriction site (PCR/ACRS) method for detection of the nine most frequent point mutations (p.P30L (c.92C>T); In2G (c.293-13A/C>G); p.G110Efs (c.332_339del); p.I172N (c.518T $>A$ ); exon 6 cluster mutations: p.I236N (c.710T>A), p.V237E (c.713T>A), p.M239K (c.719T>A); p.V281L (c.844G $>$ T); p.Leu307fs (c.923_924insT); p.Q318X (c.955C>T) and p.R356W (c.1069C>T)) in the CYP21A2 gene. Subsequent restriction analysis, visualized on $2 \%$ agarose gel electrophoresis using ethidium bromide staining allowed detection and determination of the zygosity of the mutation, as described previously (15). All patients received oral therapy with hydrocortisone in a total dose $10-25 \mathrm{mg} / \mathrm{m}^{2} /$ day divided in 3 daily doses. In patients with the SW form of the disease fludrocortisone (0.05-0.2 mg divided in 3 doses per day) was given orally prior to puberty. Therapy was titrated aiming to achieve a $17-\mathrm{OH}$ progesterone (17-OHP) level below $10 \mathrm{ng} / \mathrm{mL}$. Follow-ups were scheduled at 4-month intervals and included measurement of the height and weight (BMI), pubertal stage, testis volume and the levels of electrolytes, 17-OHP, ACTH, androstenedione and testosterone. Plasma renin activity was measured in patients with the SW form of the disease. After onset of puberty, measurement of follicle-stimulating hormone (FSH) and luteinizing hormone ( $\mathrm{LH})$ was added to the evaluation. FSH, LH, ACTH, androstenedione and testosterone were analyzed with chemiluminescence (IMMULITE 2000, SIEMENS), whereas17-OHP was analyzed with ELISA (Chemwell analyzer, FL, USA). The metabolic control was evaluated yearly. If the appropriate dose of hydrocortisone was prescribed, the 17-OHP, androstenedione and ACTH levels and linear growth above $10 \%$ on the standard growth curve were indicators of metabolic control and compliance. In pubertal boys, s.D. for predicted midparental height was calculated. Arbitrarily, patients who had $\geq 70 \%$ of 17 -OHP measurements equal or below $10 \mathrm{ng} / \mathrm{mL}$ accompanied with normal ACTH levels were considered to be under satisfactory metabolic control and adherent to therapy. Comparison of the metabolic parameters, BMI and height were compared between the adherent and non-adherent group of patient.

Testicular ultrasonographic examination was introduced in 2001 and was initiated at the age of 
4 years and repeated yearly. All patients were examined by the same trained doctor on the technical equipment SonoScape SSI-5000 (Providan Medical Equipment, Highland Heights, OH, USA). Longitudinal and transverse axes of the testes and TART, when visible, were measured. The ultrasonographic finding was classified in five stages as previously described (16). Magnetic resonance imaging (MRI) of the testes was performed in the first 5 patients with TART. Biopsy of the testicular tumor was performed in 2 patients who had a large tumor on ultrasonography. Slides were immunohistochemically stained with antibodies against alpha-inhibin, melanA, calretinin, synaptophysin, chromogranin, vimentin, CD56 and CD10 and analyzed on the microscope Olympus BX 41. Sperm examination was performed in two adolescents at 18 years.

\section{Ethical approval}

Procedures performed in studies involving human participants were in accordance with the ethical standards of the institutional and/or national research committee and with the 1964 Helsinki Declaration and its later amendments or comparable ethical standards.

\section{Results}

During the period 1991-2015, 71 Macedonian patients were diagnosed with CAH (26 with SW form, 21 with SV and 24 with non-classic (NC). In the 30 males analyzed for this study in the period 2001-2016, the following disease forms were noted: SW in 16 (53.3\%), SV in 9 (30\%) and NC in $5(16.7 \%)$. From 2005, we have systematically followed 25 boys in the age group 4-18 years during a 10-year period and diagnosed eight of them (32\%) with TART. Five of the patients with TART had severe SW form, two had SV form and one NC form of the disease. Molecular analysis confirmed severe mutations in six. One patient was homozygous for the p.I172N (c.518T>A) mutation, typical for the SV form. One patient was homozygous for the mild p.P30L (c.92C>T) mutation, typical for the NC form (Table 1).

A total of 289 follow-up visits were performed prior to the diagnosis of TART (6-28 per patient). Therapy with hydrocortisone was tailored according to the 17-OHP levels. Of the 8 patients with TART, 3 were under satisfactory metabolic control. The remaining 5 were under poor metabolic control during various periods of the study. Children non-adherent to treatment in both groups with and without TART had higher 17OHP and androstenedione levels, whereas no significant difference in the height, BMI or onset of puberty was revealed (Table 2). When we compared clinical and laboratory values between children with and with no TART, these significances were lost (Table 3). Thus, all analyzed data were similar in children with and without TART.

The ratio of patients under good metabolic control was similar in the group without TART $(6 / 17$ vs $3 / 8)(P=0.17)$. It should be noted that two boys with TART (both noncompliant) each had a non-compliant brother with the same CYP21A2 mutation, but neither of them had TART. One patient had large, palpable tumors on both testes; he had been consistently non-compliant for the prescribed therapy (Table 1). FSH, LH and testosterone values during the follow-up were different depending on the stage of puberty (data not shown).

A total of 123 yearly testicular ultrasonography examinations (1-10 per patient) were performed during the study period, out of which 39 in the patients with TART. The children who reached adolescence during this period were followed up until the age of 21 years when they were referred to an adult endocrinologist. In the three youngest patients with early ultrasonographic examination at the ages of 7, 10 and 11 years, respectively, the tumor size was $4-10 \mathrm{~mm}$ in diameter, whereas in the older patients (aged $12-18$ years) the size reached $12-35 \mathrm{~mm}$. TARTs were localized mostly around the rete testis (Fig. 1). When TART was detected, we continued to follow-up patients at 2-month intervals in order to keep the 17-OHP values within the appropriate levels. In 6 patients whose 17-OHP levels improved, TART decreased or did not progress during 2-4 years of follow-up (Table 1). However, in two other patients, the tumor increased despite the changes in dose of hydrocortisone and improved metabolic control (Fig. 2).

MRI was performed in 5 boys with TART detected on ultrasound. It confirmed the distribution of the TARTs around the hilus of the testis in all of the patients (Fig. 3). However, since no significant contribution to the diagnosis was achieved, we did not perform it in the remaining boys. In two boys with large TARTs testicular biopsy was performed. In one of them (patient 3), Leydig cell tumor was considered histologically and additional staining methods and follow-up were required to confirm TART. Microscopically, the testicular core biopsy of the two patients showed similar morphological features. Sheets and nests of uniform large, polygonal cells with abundant eosinophilic cytoplasm and round central nuclei were found. Some of the cells contained lipochrome http://www.endocrineconnections.org https://doi.org/10.1530/EC-18-0097
(C) 2018 The authors Published by Bioscientifica Ltd

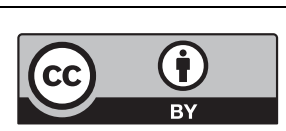

This work is licensed under a Creative Commons Attribution 4.0 International License. 
pigment. There was mild nuclear pleomorphism without mitotic activity. The sheets and nests were separated by thin fibrous septa. Reinke's crystals were not found. Both cases showed positive diffuse or patchy staining for alpha-inhibin, melanA, calretinin, CD56, synaptophysin and chromogranin, consistent with TART (Fig. 4). Sperm examination showed normal semen volume with decreased sperm concentration in two boys at 18 years of age.

One severely non-compliant adolescent with TART developed mixed lymphoblastic/myeloblastic leukemia at the age of 16 years, resistant to therapy and with lethal outcome within one year.

\section{Discussion}

TARTs in male patients with CAH have been analyzed in many studies and the quest for risk factors for this complication is still not complete $(11,13,16,17)$. TART has been found in 30-94\% of adults with CAH $(4,11,12,18,19)$ using testicular ultrasound. Although substantial evidence suggests that TART is frequently present in adolescence, studies in children searching for the first symptoms of TART are of more recent dates, the prevalence of TART in children being in the range of $18.3-48 \%(8,20)$. TART has been confirmed in a child as young as 4 years (20), 6 years and 7.5 years (16), but it is rare before adolescence. Systematic ultrasonographic search for TART in children has rarely been reported in the literature. By yearly ultrasonographic examinations during a 15-year period, we found TART in 8 out of 25 boys with CAH (32\%), three of them very young, aged 6 , 10 and 11 years, respectively.

In patients with $\mathrm{CAH}$ therapeutic non-compliance or inadequate treatment can contribute to TART development $(9,10,19)$. High levels of ACTH might start the process of adrenal cell stimulation in the testes even prenatally $(12,16)$.

Difficulties to maintain good hormonal control are frequent in patients with $\mathrm{CAH}$, especially during puberty due to hormonal changes influencing the adrenal androgens, but also due to pubertal psychosocial issues and non-compliance $(16,17,21)$. Temporary changes in the metabolic control are more often the rule than the exception. Steady continuous metabolic control is found in only one-third of patients $(21,22)$. In a study of 11 boys with TART, Aycan et al. detected only 2 patients under tight metabolic control, but they did not describe the control in the other 49 boys without TART (20). Finkelstein et al.

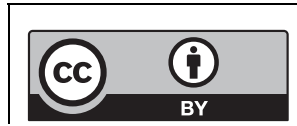


Table 2 A comparison of the clinical and biochemical parameters of CAH patients adherent and non-adherent to treatment both who did or did not developed TART at the time of the last scrotal ultrasound examination (mean \pm S.D. or median and range).

\begin{tabular}{l} 
\\
\hline Age at \\
evaluation \\
(years) \\
$170 H P(n g / d L)$ \\
(0.2-2.3) \\
Androstenedione \\
(ng/mL) \\
(0.6-2.7) \\
Testosterone \\
(nmol/L) \\
(8.5-55.5) \\
Height (SDS) \\
BMI (SDS) \\
Age at puberty \\
(years)*
\end{tabular}

$\frac{\text { Adherent }}{\frac{\text { TART (3/8) }}{14.1 \pm 1.3}} \frac{\text { No TART (6/17) }}{16.2 \pm 1.7}$

$\frac{\frac{\text { TART + no TART }}{9 / 25}}{15.7 \pm 2.6}$

\begin{tabular}{|c|c|}
\hline \multicolumn{2}{|c|}{ Non-adherent } \\
\hline TART (5/8) & No TART $(11 / 17)$ \\
\hline $16.5 \pm 2.3$ & $14.6 \pm 3.1$ \\
\hline
\end{tabular}

$\frac{\frac{\text { TART + no TART }}{16 / 25}}{15.0 \pm 2.7} \frac{\boldsymbol{P}}{\text { NS }}$

$\begin{array}{rrr}9.7 \pm 2.2 & 11.1 \pm 5.2 & 10.3 \pm 4.1 \\ 16.2 \pm 4.3 & 12.4 \pm 4.1 & 14.2 \pm 2.6\end{array}$

$19.3 \pm 1.9$

$16.3 \pm 2.3$

$17.6 \pm 3.4$

$<0.001$

$20.2 \pm 2.3$

$18.8 \pm 4.7$

$19.6 \pm 3.9$

$<0.01$

$32.0 \pm 15.3 \quad 26.6 \pm 15.2$

$29.8 \pm 21.1$

$30.0 \pm 14.2$

$28.1 \pm 12.2$

$29.1 \pm 13.6$

NS

$-1.1(-0.9 /-1.3)-1.2$

$0.42+0.2$

$0.35 \pm 0.6$

$-1.1(-0.8 /-1.3)$

$0.39 \pm 0.5$
$-1.3(-1.2 /-1.4)-1.3$
$0.52 \pm 0.9$

$1.3(-1.0 /-1.6)$
$0.47 \pm 1.3$

$-1.3(-1.0 /-1.6)$

$0.49 \pm 1.2$

$12.2(11.9-13.1) \quad 12.7(11.6-12.9) \quad 12.5(11.6-12.0)$

$11.5(11.0-12.5) \quad 12.3(11.6-12.8)$

$12.1(11-12.8)$

NS

NS

NS

* Puberty was assessed by initial increase of the testicular volume presented as mean and range in brackets.

$17 \mathrm{OHP}, 170 \mathrm{H}$ progesterone; NS, non-significant, normal values are given in brackets; SDS, standard deviation score, TART, testicular adrenal rest tumor.

followed 244 patients with $\mathrm{CAH}$ and concluded that inappropriate control and adverse outcomes including TART are common (33\% of boys and $44 \%$ of men with CAH) (18). However, TART can appear in well-controlled and even over-treated patients with CAH $(13,23)$. In our study, three out of 8 patients with TART were well controlled. However, only 6 out of 17 patients without TART were under tight metabolic control in more than $75 \%$ of visits. The reason for worsening of the metabolic parameters is not always easy to assess because of the variable therapeutic compliance. The parents of Patient 3 found a large number of hidden hydrocortisone tablets during home relocation. On the other hand, in our study, two pairs of brothers with the SW form of CAH were

Table 3 A comparison of clinical and biochemical data in patients with and without TART (mean \pm S.D. or median and range).

\begin{tabular}{|c|c|c|c|}
\hline & TART $(8 / 25)$ & No TART (17/25) & $\boldsymbol{P}$ \\
\hline $\begin{array}{l}\text { Age at evaluation } \\
\text { (years) }\end{array}$ & $15.3 \pm 1.4$ & $15.5 \pm 2.7$ & \\
\hline $\begin{array}{l}170 \mathrm{OP}(\mathrm{ng} / \mathrm{dL}) \\
(0.2-2.3)\end{array}$ & $15.1 \pm 3.2$ & $13.2 \pm 3.5$ & NS \\
\hline $\begin{array}{l}\text { Androstenedione } \\
(\mathrm{ng} / \mathrm{mL})(0.6-2.7)\end{array}$ & $18.2 \pm 3.8$ & $16.3 \pm 3.2$ & NS \\
\hline $\begin{array}{l}\text { Testosterone } \\
(\mathrm{nmol} / \mathrm{L})(8.5-55.5)\end{array}$ & $31.0 \pm 14.9$ & $27.5 \pm 13.2$ & NS \\
\hline Height SDS (range) & $-1.1(-0.8 /-1.4)$ & $-1.3(-1.1 /-1.6)$ & NS \\
\hline BMI SDS (range) & $\begin{array}{c}+0.49 \\
(+0.35 /+0.55)\end{array}$ & $\begin{array}{c}+0.41 \\
(+0.22 /+0.63)\end{array}$ & NS \\
\hline $\begin{array}{l}\text { Age at puberty } \\
\text { (years) (range) }\end{array}$ & $11.7(11.1 / 12.2)$ & $12.5(11.5 / 13.0)$ & NS \\
\hline $\begin{array}{l}\text { http://www.endocrinecon } \\
\text { https://doi.org/10.1530/EC }\end{array}$ & $\begin{array}{l}\text { ections.org } \\
8-0097\end{array}$ & $\begin{array}{r}\text { (c) } 2018 \text { The a } \\
\text { Published by Bioscientifi }\end{array}$ & $\begin{array}{l}\text { thors } \\
\text { a Ltd }\end{array}$ \\
\hline
\end{tabular}

under similar metabolic control, but only one brother developed TART. Therefore, the compliance and the tight metabolic control is not the only factor contributing to TART $(11,17)$. Our findings are comparable with those of Stikkelbroeck et al. who described 11 patients with adequate treatment and high compliance, all of which developed TART (17). Most of the published studies
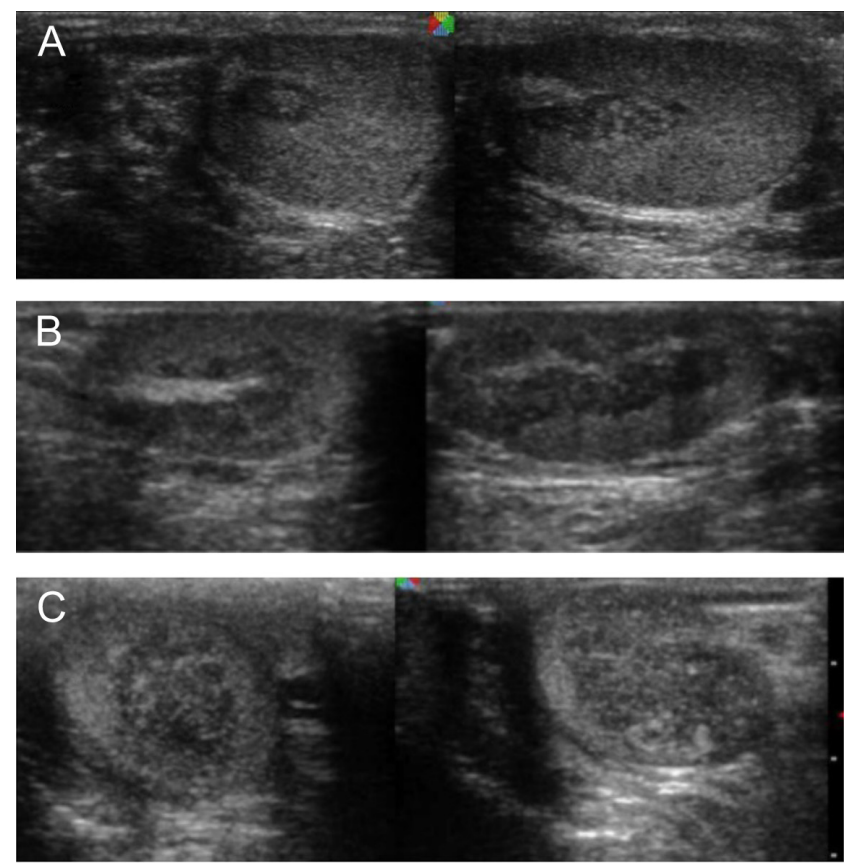

Figure 1

Testicular ultrasonography in patients showing TART location around testicular hilus. (A) Patient 6. (B) Patient 2. (C) Patient 7.

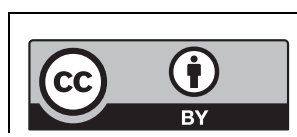

This work is licensed under a Creative Commons Attribution 4.0 International License. 

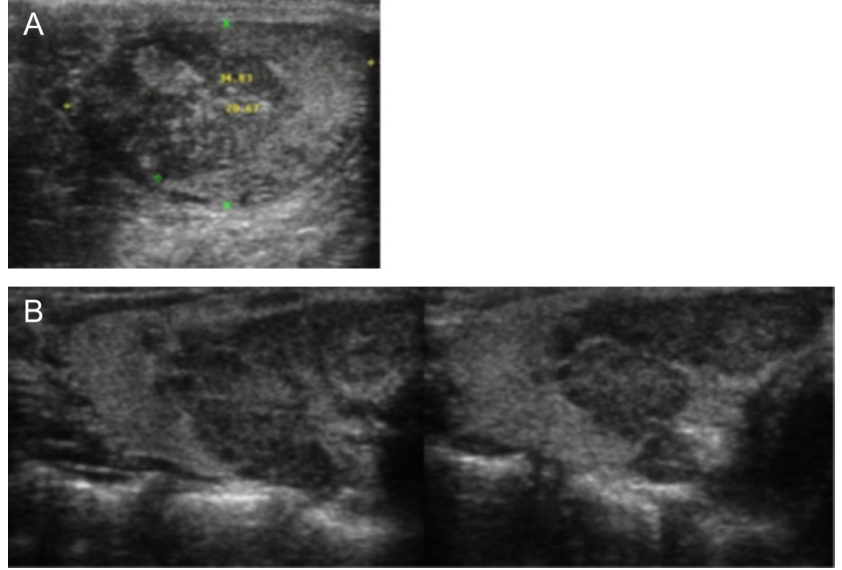

Figure 2

Patient 1 with poor metabolic control and evolution of TART within 4 years of follow-up. (A) Changes in the testicular tissue at the detection of TART. (B) TART after 4 years of poor metabolic control.

indicate that TART is associated only with classical forms of the disease, e.g. a null group carrying null mutations with no enzyme activity, a group containing In $2 \mathrm{G}$ mutations with negligible enzyme activity, or group B composed of patients with a homozygous p.I172N mutation causing the SV form of the disease with enzyme activity up to $2 \%(6$, $20,14,17)$. However, isolated cases with 11-hydroxylase and 3b-hydroxyl steroid dehydrogenase gene mutations as well as rare cases with non-classical phenotypes have also been reported $(6,24)$. Thus, all genetic groups of $\mathrm{CAH}$ can develop TART although with varying incidence. Our patients belonged to group A (five with SW form) and B (two with SV form). One of the patients was homozygous
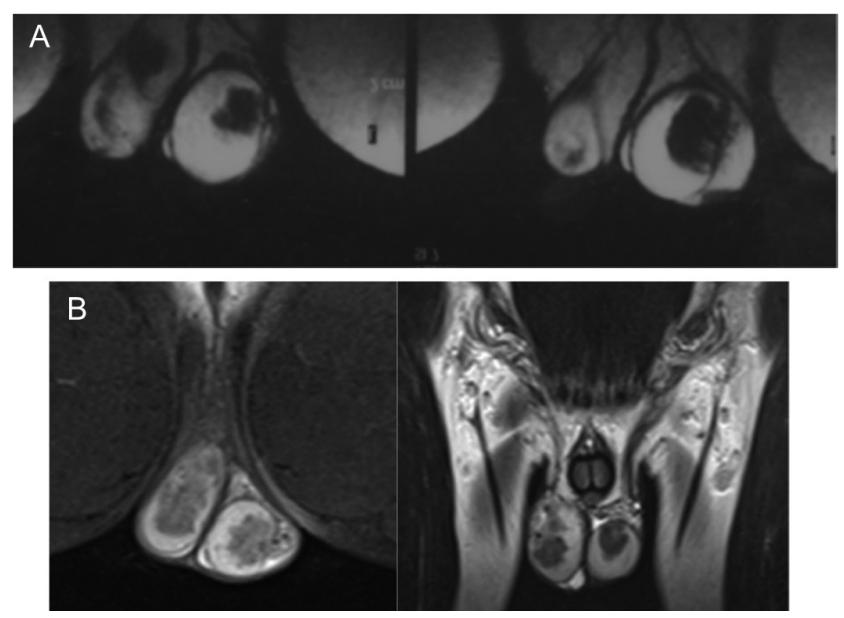

Figure 3

Testicular MRI in patients with TART. (A) Patient 1 during the follow-up, TART is spread around the testicular hilus. (B) Patient 3 with a large TART involving the entire testis. This patient underwent orchiectomy due to the significant discomfort.

$$
\begin{array}{lr}
\text { http://www.endocrineconnections.org } & \text { @ } 2018 \text { The authors } \\
\text { https://doi.org/10.1530/EC-18-0097 } & \text { Published by Bioscientifica Ltd }
\end{array}
$$

for p.P30L. This mutation is considered mild, however, when homozygous, can cause increased virilization similar to the SV form $(25,26,27)$. We have not found a patient with TART and this genotype in the literature. Having in mind that the genotype-phenotype correlation in $\mathrm{CAH}$ is not found in all patients $(2,28)$, genetic analysis of larger TART patient cohorts might discover additional genotypes that are associated with TART.

Ultrasound examination is very useful in the detection of the initial changes in the testes, staging and for the subsequent follow-up of therapy $(8,11,23)$. All our patients with TART showed changes in the structure during the follow-up. Timely detection of TART is important in order to adjust therapy and prevent long-term damage of the functional testicular tissue $(14,17)$. Spermatogenesis is affected by TART depending on the stage and extension of the testicular damage $(5,16,20,29)$. In the large study of 164 men with CAH, 34\% of whom had TART, Bouvatier et al. found significantly prevalent azoospermia in these patients compared with those who did not develop TART (4). According to Falhammar et al. patients with TART are less likely to father biological children (30). Interestingly, patients with the p.I172N genotype have been reported to have the most severe infertility due to lower sperm quality compared to patients with other severe mutations $(27,30)$. This phenomenon has not been thus far elucidated. The latest large multicenter study confirmed significant fertility impairment in adult males with $\mathrm{CAH}$ both presenting TART, and without TART suggesting that fertility should be kept in mind in all male children with CAH since the diagnosis (31).

MRI was used in some studies and isolated patients with TART. It can be helpful in confirming the initial lesions, however, most of the authors prefer the ultrasound due to the common availability and price (12, $13,16)$. We have performed it in 5 of our patients who were positive on ultrasound and it only confirmed the ultrasound findings; therefore, we would not recommend it as a routine analysis in TART. Most endocrinologists do not recommend biopsy if the other criteria (clinical, ultrasonographic, MRI) for TART are met. However, sometimes testicular biopsy is needed for histological differentiation and excluding Leydig cell tumor $(32,33)$. Usually the TART biopsy shows adrenal histology adjacent to the testicular tissue, as was the case in our patients. Rarely, TART can be associated with Leydig cell tumor $(24,34)$. In two of our patients, we performed testicular biopsy due to the size of the tumor and predominance in one of the testicles. One of them was initially diagnosed as Leydig cell tumor; however, the specific staining and

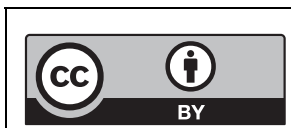

This work is licensed under a Creative Commons Attribution 4.0 International License. 

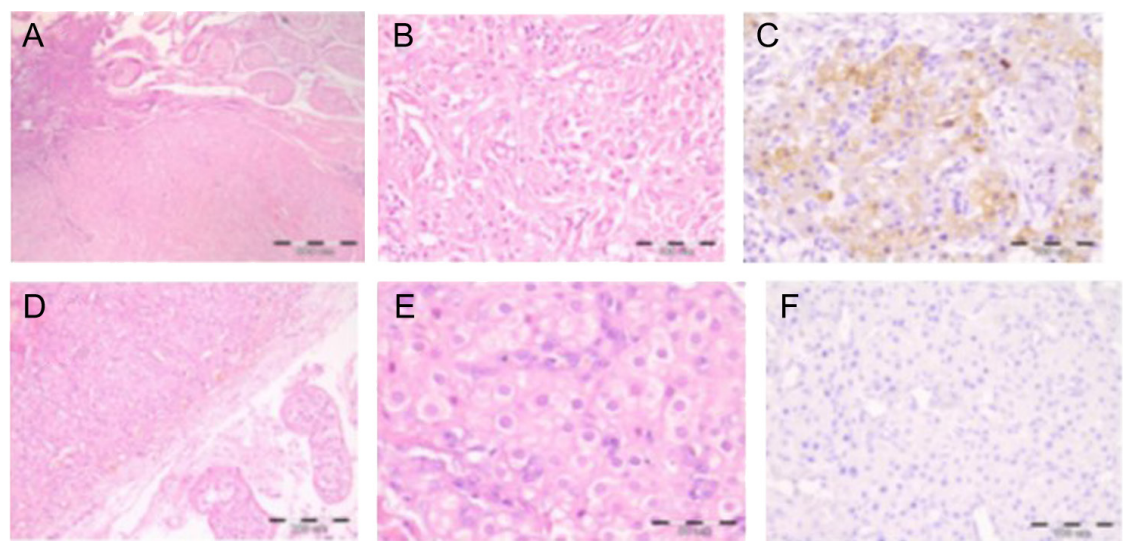

Figure 4
Histology of the testes in the two biopsied
patients. Upper line: Patient 1 . (A) The arrow
points to the delineation between adrenal and
testicular tissue. (B) Larger view. (C) Positive
inhibin staining. Lower line: Patient 3. (D)
Adrenal tissue in the testis (magnification $\times 400$ ).
(E) Closer image of the TART tissue. (F) Negative
inhibin staining.

the evolution excluded this diagnosis. The other boy had a peculiar disease course, with many challenges in the metabolic control. The biopsy confirmed TART. However, at the age of 16 years, he developed rapid progressing and therapy-resistant mixed lymphocytic/myeloblastic leukemia and died within a year of the diagnosis. To our knowledge, a similar case where TART was associated with malignancy has not been described so far and their relation remains elusive.

Several studies have shown improvements using increased doses of hydrocortisone and fludrocortisone $(22,35,36)$. While some authors refer to complete remission of the tumors after increased doses of hydrocortisone, others find temporary improvement in some patients, and no response in others $(17,20)$. In our patients, increased doses showed slight decrease of the tumor size in 3 patients and stabilization in another 3 ; there was no improvement in the remaining 2 . Side effects of higher steroid doses such as hypertension, obesity and insulin resistance have been described $(22,30$, $37)$. When no improvement with hormonal adjustment is achieved, testis sparing surgery is warranted $(33,38)$. However, TART might reappear after surgery. Preservation of sperm in young adults should also be considered while the sperm quality is still satisfactory (35).

The strengths of our study are the relatively large number of young boys with CAH followed systematically by yearly ultrasound in the same center for 15 years. The weakness is the small number of patients due to the rarity of the disease and arbitrary judgment of the metabolic control as a percentage of adequate $17 \mathrm{OHP}$ levels having in mind that some of these boys have periods of better and worse control.

In conclusion, the treatment of classical forms of $\mathrm{CAH}$ in young boys is generally suboptimal, not strictly dependent on the CYPA2 mutation, and can deteriorate towards TART development around puberty.
However, appearance at a younger age and in wellcontrolled patients shows that the continuous suboptimal control is not the single reason for TART. The contribution of the treatment, the severity of the mutation or other unknown factors remains to be elucidated. Early detection and follow-up of TART by ultrasound is useful for the preservation of testicular function.

\section{Declaration of interest}

The authors declare that there is no conflict of interest that could be perceived as prejudicing the impartiality of the research reported.

\section{Funding}

This research did not receive any specific grant from any funding agency in the public, commercial or not-for-profit sector.

\section{Author contribution statement}

M K diagnosed, treated, followed the patients, designed, wrote and edited the manuscript; $V \mathrm{~J}$ participated in the writing and editing and performed histology of testicular tissue; $V$ A performed and discussed genetic analyses and participated in the writing and editing of the manuscript.

\section{Informed consent}

Informed consent was obtained from all individual participants included in this study.

\section{Acknowledgements}

The authors acknowledge the collaboration of the patients.

\section{References}

1 Choi JH, Kim GH \& Yoo HW. Recent advances in biochemical and molecular analysis of congenital adrenal hyperplasia due to 21-hydroxylase deficiency. Annals of Pediatric Endocrinology and Metabolism 201621 1-6. (https://doi.org/10.6065/apem.2016.21.1.1)

2 White PC \& Speiser PW. Congenital adrenal hyperplasia due to 21-hydroxylase deficiency. Endocrine Reviews 200021 245-291. (https://doi.org/10.1210/edrv.21.3.0398)

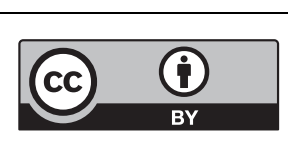

This work is licensed under a Creative Commons Attribution 4.0 International License. 
3 Baumgartner-Parzer SM, Nowotny P, Heinze G, Waldhäusl W \& Vierhapper H. Carrier frequency of congenital adrenal hyperplasia (21-hydroxylase deficiency) in a Middle European Population. Journal of Clinical Endocrinology and Metabolism 200590 775-778. (https:// doi.org/10.1210/jc.2004-1728)

4 Bouvattier C, Esterle L, Renoult-Pierre P, de la Perriere AB, Illoiz F, Kerlan V, Pascal-Vigneron V, Drui D, Maitre SC, Gallard F, et al. Clinical outcome, hormonal status, gonadotrope axis, and testicular function in 219 adult men born with classic 21-hydroxylase deficiency. A French national survey. Journal of Clinical Endocrinology and Metabolism 2015100 2303-2313. (https://doi.org/10.1210/ jc.2014-4124)

5 Reisch N, Flade L, Scherr M, Rottenkolber M, Pedrosa Gil F, Bidlingmaier M, Wolff H, Schwarz HP, Quinkler M, Beuschlein F, et al. High prevalence of reduced fecundity in man with congenital adrenal hyperplasia. Journal of Clinical Endocrinology and Metabolism 200994 1665-1670. (https://doi.org/10.1210/jc.2008-1414)

6 Falhammar H, Nyström HF, Ekström U, Granberg S, Wedell A \& Thorén M. Fertility, sexuality and testicular adrenal rest tumors in adults males with congenital adrenal hyperplasia. European Journal of Endocrinology 2012166 441-449. (https://doi.org/10.1530/EJE-11-0828)

7 Claahsen-van der Grinten HL, Otten BJ, Sweep FCG, Span PN, Rpss HA, Meuleman EJH \& Hermus ARMM. Testicular tumors in patients with congenital adrenal hyperplasia due to 21-hydroxylase deficiency show functional features of adrenocortical tissue. Journal of Clinical Endocrinology and Metabolism 200792 3874-3680. (https:// doi.org/10.1210/jc.2007-0337)

8 Claahsen-van der Grinten HL, Sweep FCGJ, Blickman JG, Hermus ARMM \& Otten BJ. Prevalence of testicular adrenal rest tumors in male children with congenital adrenal hyperplasia due to 21-hydroxylase deficiency. European Journal of Endocrinology 2007157 339-344. (https://doi.org/10.1530/EJE-07-0201)

9 Jin HY, Choi JH, Kim GH, Lee CS \& Yoo HW. Testicular adrenal rest tumors in a patient with untreated congenital adrenal hyperplasia. Korean Journal of Pediatrics 201154 137-140. (https://doi. org/10.3345/kjp.2011.54.3.137)

10 Hamwi GJ, Gwinup G, Mostow JH \& Besch PK. Activation of testicular adrenal rest tissue by prolonged excessive ACTH production. Journal of Clinical Endocrinology and Metabolism 196323 861-869. (https://doi.org/10.1210/jcem-23-9-861)

11 Delfino M, Elia J, Imbrogno N, Argese N, Mazzilli R, Toscano V \& Mazzilli F. Testicular adrenal rest tumors in patients with congenital adrenal hyperplasia: prevalence and sonographic, hormonal, and seminal characteristics. Journal of Ultrasound in Medicine 201231 383-388. (https://doi.org/10.7863/jum.2012.31.3.383)

12 Reisch N, Scherr M, Flade L, Bidlingmaier M, Schwarz HP, MüllerLisse U, Reincke M, Quinkler M \& Beuschlein F. Total adrenal volume but not testicular adrenal rest tumor volume is associated with hormonal control in patients with 21-hydroxylase deficiency. Journal of Clinical Endocrinology and Metabolism 201095 2065-2072. (https:// doi.org/10.1210/jc.2009-1929)

13 Reisch N, Rottenkolber M, Greifenstein A, Krone N, Schmidt H, Reincke M, Schwartz HP \& Beuschlein F. Testicular adrenal rest tumors develop independently of long-term disease control: a longitudinal analysis of 50 adult men with congenital adrenal hyperplasia due to classic 21-hydroxylase deficiency. Journal of Clinical Endocrinology and Metabolism 201398 E1820-E1826. (https:// doi.org/10.1210/jc.2012-3181)

14 Speiser PW, Azziz R, Baskin LS, Ghizzoni L, Hensle TW, Merke DP, Meyer-Bahlburg HFL, Miller WL, Montori VM, Oberfield SE, et al. Congenital adrenal hyperplasia due to 21-hydroxylase deficiency: an endocrine society clinical practice guideline. Journal of Clinical Endocrinology and Metabolism 201095 4133-4160. (https://doi. org/10.1210/jc2009-2631)

15 Anastasovska V \& Kocova M. Genotype-phenotype correlation in $\mathrm{CAH}$ patients with severe CYP21A2 point mutations in the Republic of Macedonia. Journal of Pediatric Endocrinology and Metabolism 2010 23 921-926. (https://doi.org/10.1515/jpem.2010.147)

16 Claahsen-van der Grinten HL, Otten BJ, Stikkelbroeck MM, Sweep FC $\&$ Hermus AR. Testicular adrenal rest tumours in congenital adrenal hyperplasia. International Journal of Pediatric Endocrinology 20092009 624823. (https://doi.org/10.1155/2009/624823)

17 Stikkelbroeck NMML, Otten BJ, Pasic A, Jager GJ, Sweep CGJ, Noordam K \& Hermus ARMM. High prevalence of testicular adrenal rest tumors, impaired spermatogenesis, and Leydig cell failure in adolescent and adult males with congenital adrenal hyperplasia. Journal of Clinical Endocrinology and Metabolism 200186 5721-5728. (https://doi.org/10.1210/jcem.86.12.8090)

18 Finkielstain GP, Kim MS, Sinaii N, Nishitani M, Van Ryzin C, Hill SC, Reynolds JC, Hanna RM \& Merke DP. Clinical characteristics of a cohort of 244 patients with congenital adrenal hyperplasia. Journal of Clinical Endocrinology and Metabolism 201297 4429-4438. (https:// doi.org/10.1210/jc.2012-2102)

19 Dumic M, Duspara V, Grubic Z, Oguic SK, Skrabic V \& Kusec V. Testicular adrenal rest tumors in congenital adrenal hyperplasiacross-sectional study of 51 Croatian male patients. European Journal of Pediatrics 2017176 1393-1404. (https://doi.org/10.1007/s00431-0173008-7)

20 Aycan Z, Bas VN, Cetinkaya S, Yilmaz Agladioglu S \& Tiryaki T. Prevalence and long-term follow-up outcomes of testicular adrenal rest tumours in children and adolescent males with congenital adrenal hyperplasia. Clinical Endocrinology 201378 667-672. (https:// doi.org/10.1111/cen.12033)

21 Auchus RJ \& Arlt W. Approach to the patient: the adult with congenital adrenal hyperplasia. Journal of Clinical Endocrinology and Metabolism 201398 2645-2655. (https://doi.org/10.1210/jc.20131440)

22 Han TS, Walker BR, Arlt W \& Ross RJ. Treatment and health outcomes in adults with congenital adrenal hyperplasia. Nature Reviews Endocrinology 201410 115-124. (https://doi.org/10.1038/ nrendo.2013.239)

23 Avila NA, Shawker TS, Jones JV, Cutler GB Jr \& Merke DP. Testicular adrenal rest tissue in congenital adrenal hyperplasia: serial sonographic and clinical findings. American Journal of Roentgenology 1999172 1235-1238. (https://doi.org/10.2214/ ajr.172.5.10227495)

24 Charfi N, Kamoun M, FekiMnif M, Mseddi N, Mnif F, Kallel N, Ben Naceur B, Rekik N, Fourati H, Daoud E, et al. Leydig cell tumor associated with testicular adrenal rest tumors in a patient with congenital adrenal hyperplasia due to $11 ß$-hydroxylase deficiency. Case Reports in Urology 20122012 648643. (https://doi. org/10.1155/2012/648643)

25 Anastasovska V, Kocova E \& Kocova M. A p.P30L mutation at the CYP21A2 gene in Macedonian patients with nonclassical congenital adrenal hyperplasia. Balkan Journal of Medical Genetics 201013 19-23. (https://doi.org/10.2478/v10034-010-0014-8)

26 Krone N, Braun A, Roscher AA, Knorr D \& Schwarz HP. Predicting phenotype in steroid 21-hydroxylase deficiency? Comprehensive genotyping in 155 unrelated, well defined patients from southern Germany. Journal of Clinical Endocrinology and Metabolism 200085 1059-1065. (https://doi.org/10.1210/jcem.85.3.6441)

27 Tusie-Luna MT, Speiser PW, Dumic M, New MI \& White PC. A mutation (Pro30 to Leu) in CYP21 represents a potential nonclassic steroid 21-hydroxylase deficiency allele. Molecular Endocrinology 1991 5 685-692. (https://doi.org/10.1210/mend-5-5-685)

28 Wilson RC, Mercado AB, Cheng KC \& New MI. Steroid 21-hydroxylase deficiency: genotype may not predict phenotype. Journal of Clinical Endocrinology and Metabolism 199580 2322-2329. (https://doi.org/10.1210/jcem.80.8.7629224)

29 Gidlöf S, Falhammar H, Thilén A, von Döbeln U, Ritzén M, Wedell A $\&$ Nordenström A. One hundred years of congenital adrenal hyperplasia in Sweden: a retrospective, population-based cohort

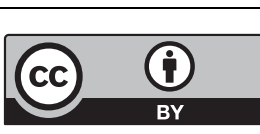


study. Lancet Diabetes and Endocrinology 20131 35-42. (https://doi. org/10.1016/S2213-8587(13)70007-X)

30 Falhammar H, Frisen L, Norroby C, Almqvist C, Linden H, Nordenskjold A \& Nordenstrom A. Reduced frequency of biological and increase frequency of adopted children in males with 21-hydroxylase deficinency: a Swedish population-based national cohort study. Journal of Clinical Endocrinology and Metabolism 2017 102 4191-4199. (https://doi.org/101210/jc.2017-01139)

31 Engels M, Gehrmann K, Falhammar H, Webb EA, Nordenström A, Sweep FC, Span PN, van Herwaarden AE, Rohayem J, RichterUnruh A, et al. Gonadal function in adult male patients with congenital adrenal hyperplasia. European Journal of Endocrinology 2018178 285-294. (https://doi.org/10.1530/EJE-17-0862)

32 Ali HH, Samkari A \& Arabi H. Testicular adrenal rest "tumor" or Leydig cell tumor? A report of a challenging case with literature review. Avicenna Journal of Medicine 20133 15-19. (https://doi. org/10.4103/2231-0770.112789)

33 Rajkanna J \& Oyibo SO. Large terticular adrenal rest tumours in a patient with congenital adrenal hyperplasia. Endocrinology, Diabetes and Metabolism Case Reports 20152015 140080. (https://doi. org/10.1530/EDM-14-0080)
34 Santoriello A, Benevento R, Petronella P, Perna G \& Canonico S. Congenital adrenal hyperplasia and Leydig cell tumor of testis. Case report and review of literature. Annali Italiani di Chirurgia 201081 445-448.

35 Falhammar H \& Thorén M. Clinical outcomes in the management of congenital adrenal hyperplasia. Endocrine 201241 355-373. (https:// doi.org/10.1007/s12020-011-9591-x)

36 Kim JH, Choi JH, Kang E, Kim YM, Lee BH \& Yoo HW. Long-term consequences of congenital adrenal hyperplasia due to classic 21-hydroxylase deficiency in adolescents and adults. Experimental and Clinical Endocrinology and Diabetes 2017125 196-201. (https://doi. org/10.1055/s-0042-123037)

37 Arlt W, Willis DS, Wild SH, Krone N, Doherty EJ, Hahner S, Han TS, Carroll PV, Conway GS, Rees DA, et al. Health status of adults with congenital adrenal hyperplasia: a cohort study of 203 patients. Journal of Clinical Endocrinology and Metabolism 201095 5110-5121. (https://doi.org/10.1210/jc.2010-0917)

38 Walker BR, Skoog SJ, Winslow BH, Canning DA \& Tank ES. Testis sparing surgery for steroid unresponsive testicular tumors of the adrenogenital syndrome. Journal of Urology 1997157 1460-1463. (https://doi.org/10.1097/00005392-199704000-00103)

Received in final form 5 March 2018

Accepted 12 March 2018

Accepted Preprint published online 12 March 2018 http://www.endocrineconnections.org https://doi.org/10.1530/EC-18-0097
() 2018 The authors Published by Bioscientifica Ltd

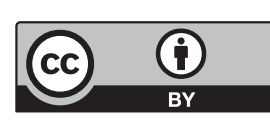

This work is licensed under a Creative Commons Attribution 4.0 International License. 